\title{
PAPERS
}

\section{A randomised controlled comparison of injection, thermal, and mechanical endoscopic methods of haemostasis on mesenteric vessels}

\author{
C C Hepworth, S S Kadirkamanathan, F Gong, C P Swain
}

\begin{abstract}
Background and aims-A randomised controlled comparison of haemostatic efficacy of mechanical, injection, and thermal methods of haemostasis was undertaken using canine mesenteric vessels to test the hypothesis that mechanical methods of haemostasis are more effective in controlling haemorrhage than injection or thermal methods. The diameter of arteries in human bleeding ulcers measures up to $3.45 \mathrm{~mm}$; mesenteric vessels up to $5 \mathrm{~mm}$ were therefore studied.
\end{abstract}

Methods-Mesenteric vessels were randomised to treatment with injection sclerotherapy (adrenaline and ethanolamine), bipolar diathermy, or mechanical methods (band, clips, sewing machine, endoloops). The vessels were severed and haemostasis recorded.

Results-Injection sclerotherapy and clips failed to stop bleeding from vessels of 1 $\mathrm{mm}(\mathrm{n}=20)$ and $2 \mathrm{~mm}(\mathrm{n}=20)$. Bipolar diathermy was effective on $8 / 10$ vessels of 2 mm but failed on $3 \mathrm{~mm}$ vessels $(n=5)$. Unstretched elastic bands succeeded on $13 / 15$ vessels of $2 \mathrm{~mm}$ but on only $3 / 10$ vessels of $3 \mathrm{~mm}$. The sewing machine achieved haemostasis on $8 / 10$ vessels of 4 mm but failed on $5 \mathrm{~mm}$ vessels $(n=5)$; endoloops were effective on all $5 \mathrm{~mm}$ vessels $(\mathbf{n}=5)$.

Conclusions-Only mechanical methods were effective on vessels greater than 2 $\mathrm{mm}$ in diameter. Some mechanical methods (banding and clips) were less effective than expected and need modification. Thermal and (effective) mechanical methods were significantly $(p<0.01)$ more effective than injection sclerotherapy. The most effective mechanical methods were significantly more effective $(p<0.01)$ than thermal or injection on vessels greater than 2 mm.

(Gut 1998;42:462-469)

Keywords: endoscopic haemostasis; mesenteric vessels

Dr P Swain

London Hospital,

Whitechapel,

London E1 1BB, UK.

Accepted for publication 13 November 1997
Although endoscopic therapy ${ }^{1-3}$ with laser, ${ }^{4-9}$ thermal probe,,$^{810-13}$ or injection sclero- therapy ${ }^{14-19}$ for bleeding peptic ulcers seems more effective than medical therapy alone, rebleeding is still common with reported rebleeding rates of $5 \%,{ }^{19} 6 \%,{ }^{11} 122010 \%,{ }^{420} 21$ $12 \%,{ }^{22} \quad 15 \%,{ }^{23-25} \quad 16 \%,{ }^{16}{ }^{26} 17 \%,{ }^{27} 18 \%,{ }^{13}{ }^{28}$ $20 \%,{ }^{72} 22 \%,{ }^{29} 25 \%,{ }^{30} 30 \%,{ }^{31}$ and $40 \% .^{14}{ }^{15}$ Examples from published randomised studies of endoscopic haemostatic methods show rebleeding rates of up to $75 \%\left(0 \%,{ }^{11} 212532\right.$ $20 \%,{ }^{4} 22 \%,{ }^{33} 31 \%,{ }^{30} 33 \%,{ }^{21} 40 \%,{ }^{25} 46 \%,{ }^{31}$ $55 \%,{ }^{922}{ }^{22}$ and $75 \%{ }^{10}$ ) for spurting vessels and up to $27 \%\left(4 \%,{ }^{23} 6 \%,{ }^{25} 14 \%,{ }^{43} 18 \%,{ }^{25}\right.$ $20 \%,{ }^{5}{ }^{10} 2223 \%,{ }^{9}$ and $27 \%{ }^{30}$ ) for non-bleeding visible vessels. Vessels of external diameter of up to $3.45 \mathrm{~mm}$ are found in both the duodenum $^{34}$ and stomach ${ }^{34}{ }^{35}$ in patients dying from bleeding peptic ulcer and experimental studies have shown that injection sclerotherapy is ineffective in animal models on vessels over $0.5 \mathrm{~mm}^{36}{ }^{37}$ in external diameter, while thermal methods are only effective on vessels up to 2 $\mathrm{mm}^{38-43}$ in external diameter. Although direct extrapolation from animal data to human clinical studies may not be appropriate these data suggest that the most commonly used interventional endoscopic haemostatic methods may be ineffective in stopping bleeding from large vessels in ulcers.

At open surgery mechanical methods of haemostasis - sewing or clipping - are used on large vessels and thermal methods used only for small vessels. Surgeons use neither injection techniques nor diathermy, but thread ${ }^{445}$ to treat bleeding peptic ulcers at open surgery.

Endoscopic mechanical methods that have been used to achieve haemostasis clinically in patients with upper gastrointestinal haemorrhage include: haemoclip (in both variceal ${ }^{46}$ and non-variceal ${ }^{47}{ }^{48}$ haemorrhage); band ligation (in both variceal ${ }^{49-54}$ and non-variceal haemorrhage ${ }^{55}{ }^{56}$ ); and endoloop ${ }^{57}$ (a detachable snare designed for achieving haemostasis following excision of polyps and troublesome bleeding from the stalk of the polyp, which has been reported to be of use in eradicating gastric varices ${ }^{58}$ in a preliminary report of 10 patients). Other mechanical endoscopic methods that have been occasionally used clinically include: Escourou's screw, ${ }^{59}$ used to stop bleeding in standard canine experimental ulcers and in two humans with gastric ulcers; and duodenal 
balloon tamponade ${ }^{60}$ endoscopically placed in three patients to stop bleeding from the first part of the duodenum. Endoscopic devices that have been used only in experimental animal studies include an endoscopic sewing machine, ${ }^{61}$ a stapling device, ${ }^{62}$ and an ulcer clamp, ${ }^{63}$ all of which have been used to stop bleeding in standard canine experimental ulcers.

Mechanical endoscopic methods in present use clinically include band ligation, clips, and endoloops. These mechanical methods have not been evaluated in animal models to assess their efficacy on different vessel size, and no published studies exist comparing mechanical methods with injection or thermal methods in experimental models.

The following study was undertaken to test the hypothesis that mechanical methods in current use clinically, together with the sewing machine, might be more effective than injection sclerotherapy or thermal methods in achieving haemostasis on vessels of the sizes that are found in bleeding human peptic ulcers.

\section{Materials and methods}

Each of the mechanical methods to be used was initially applied to postmortem canine gastric mucosa on 20 occasions to gain familiarity with their use.

CANINE MODEL

Six adult beagles (14-17 kg, median $15 \mathrm{~kg}$ ) were studied. Anaesthesia was induced with 10 $\mathrm{mg} / \mathrm{kg}$ methohexitone sodium (Eli Lilly \& Co. Ltd, Basingstoke, UK) followed by endotracheal intubation, and maintained with nitrous oxide (BOC, Surrey, UK), oxygen (BOC), and fluothane (ICI, Cheshire, UK). Normal saline, administered intravenously, replaced fluid loss.

A laparotomy was performed via an abdominal midline incision and small bowel mesenteric vessels were identified. By utilising smaller vessels close to the serosal edge of the bowel or larger ones close to the root of the mesentery the outside diameters of vessels measuring $1 \mathrm{~mm}$ to $5 \mathrm{~mm}$ inclusive were identified and measured using a metal ruler.

Because of the anatomical arterial arcade in the small bowel mesentery, bleeding can occur from both sides of the severed artery (this can also apply to the eroded vessel in a bleeding peptic ulcer). The haemostatic method was therefore applied both proximally and distally ( $1 \mathrm{~cm}$ apart) to a mesenteric vessel of measured external diameter, before the haemostatic efficacy was tested by severing the vessel in the middle. Any bleeding was recorded as a failure to achieve haemostasis. Active bleeding was observed from both cut ends of the severed vessel and spurting was seen when larger vessels were severed.

RANDOMISATION OF MECHANICAL OR INJECTION METHODS

For randomisation, a series of sealed envelopes was opened to show which haemostatic method was to be used. The operator was unaware of the treatment modality to be used before selecting the mesenteric vessels. Vessels of diameter $1 \mathrm{~mm}$ to $5 \mathrm{~mm}$ (in $1 \mathrm{~mm}$ increments) were tested.

Each envelope included a haemostatic method to be used (in groups of five) on mesenteric vessels, beginning with vessels of 1 $\mathrm{mm}$ diameter. If haemostasis was achieved, the haemostatic method was applied to the next vessel of increasing diameter. If a method failed to achieve the expected haemostatic efficacy suggested by clinical studies, more experiments (in groups of five) were carried out to confirm the initial result.

When it was obvious that a haemostatic method was ineffective on a particular vessel size, no vessels with a larger diameter were tested. This was due to the fact that blood loss from these larger vessels would have been significant and resulted in the use of further animals. Further experiments were also performed on vessels, when it was found that by increasing the size of the vessel there was a notable loss of haemostatic efficacy.

\section{INJECTION SCLEROTHERAPY}

Adrenaline 1/10 000 (Martindale Pharmaceuticals, Romford, UK) was injected in three $2 \mathrm{ml}$ aliquots $(6 \mathrm{ml}$ in total) around and into the vessel followed by $2 \mathrm{ml}$ of ethanolamine oleate (5\% wt/vol; Martindale Pharmaceuticals, Romford, UK). Injection was delivered using a $2.2 \mathrm{~mm}$ (outer diameter) varices injection needle (Wilson Cook TWIV/6F, Wilson Cook, Letchworth, UK).

THERMAL METHOD

Bipolar diathermy was applied using a $50 \mathrm{~W}$ generator and a $3.2 \mathrm{~mm}$ bipolar electrode (BICAP probe) at 5.5 settings, giving 10 two second pulses of coagulation (ACM, München, Germany) using firm pressure on the vessel during diathermy. This bipolar electrode cannot be passed through a conventional gastroscope with a $2.8 \mathrm{~mm}$ diameter biopsy channel, but requires a gastroscope with a larger $3.8 \mathrm{~mm}$ diameter biopsy channel.

MECHANICAL METHODS

A GIF-IT20 gastroscope (Olympus) was used for the injection, band ligation, clips, endoloops, and diathermy. The sewing machine was mounted on a GIF-PQ20 (Olympus) gastroscope

\section{Endoscopic band ligation}

This was performed according to Van Stiegman et al. ${ }^{64}$ Latex rubber bands (CR Bard Inc., Billerica, USA), in the form of preassembled "O" rings (bands placed on an inner plastic cylinder) administered via an endoscopic variceal ligator (CR Bard). The neoprene bands had a mean external diameter of $5.1 \mathrm{~mm}$ (range 5.0-5.3, $\mathrm{n}=5$ ) and a mean internal diameter of $2.0 \mathrm{~mm}$ (range 1.9-2.1, $\mathrm{n}=5$ ) when unloaded from the inner cylinder. These bands probably have a smaller diameter before they are placed on the $\mathrm{O}$ ring. Unstretched black latex haemorrhoidal bands (Downs, Sheffield, UK) had a mean external diameter of $4.5 \mathrm{~mm}$ (range 4.5-4.7, $\mathrm{n}=5$ ) and a mean internal 


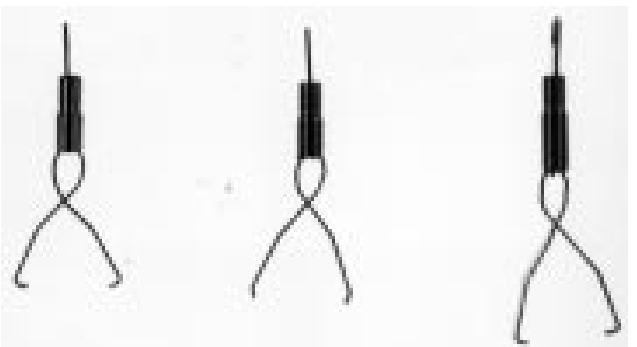

Figure 1 Marker, haemostatic, and prototype clips (left to right).

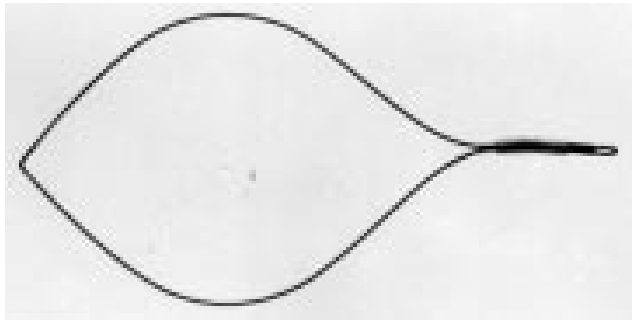

Figure 2 A nylon endoloop.

diameter of $1.4 \mathrm{~mm}$ (range 1.3-1.5, $\mathrm{n}=5$ ). These were loaded onto the inner cylinder using a conical mounting device made by us.

Endoscopic clips

Three types of endoscopic clip (Olympus, Keymed, Southend-on-Sea, UK) were used: marker (MD 59), haemostatic (MD 850), and a prototype version of the newly released $\mathrm{MH}$ 858. The marker (MD 59) and the longer prototype had a 90 degree angulation at their tip (fig 1) while the MD 850 was at 135 degrees.

Table 1 Statistical significance of one haemostatic method versus another on 1-5 mm mesenteric vessels

\begin{tabular}{|c|c|c|c|c|c|}
\hline & \multicolumn{5}{|c|}{ Mesenteric vessel diameter $(\mathrm{mm})$} \\
\hline & 1 & 2 & 3 & 4 & 5 \\
\hline \multicolumn{6}{|l|}{ Injection versus } \\
\hline Marker clip & NS & NS & NS & & \\
\hline Haemostatic clip & NS & NS & NS & & \\
\hline Prototype clip & NS & NS & NS & & \\
\hline Elastic bands & $<0.0001$ & $<0.0001$ & NS & & \\
\hline Bipolar diathermy & $<0.0001$ & $<0.0001$ & NS & & \\
\hline Sewing machine & $<0.0001$ & $<0.0001$ & 0.008 & & \\
\hline Endoloop & $<0.0001$ & $<0.0001$ & 0.008 & & \\
\hline \multicolumn{6}{|l|}{ Clips } \\
\hline Haemostatic $v$ prototype & NS & NS & NS & & \\
\hline Marker $v$ haemostatic & NS & NS & NS & & \\
\hline Marker $v$ prototype & NS & NS & NS & & \\
\hline \multicolumn{6}{|l|}{ Unstretched bands versus } \\
\hline Marker clip & 0.0011 & $<0.0001$ & 0.03 & & \\
\hline Haemostatic clip & 0.0003 & 0.0001 & NS & & \\
\hline Prototype clip & 0.008 & 0.0014 & NS & & \\
\hline Bipolar diathermy & NS & NS & NS & & \\
\hline Endoloop & NS & NS & 0.0256 & & \\
\hline \multicolumn{6}{|l|}{ Bipolar diathermy versus } \\
\hline Sewing machine & NS & NS & 0.008 & & \\
\hline Marker clip & $<0.0001$ & 0.0003 & NS & & \\
\hline Haemostatic clip & $<0.0001$ & 0.0007 & NS & & \\
\hline Prototype clip & 0.0003 & 0.007 & NS & & \\
\hline Endoloop & NS & NS & & & \\
\hline \multicolumn{6}{|l|}{ Sewing machine versus } \\
\hline Marker clip & 0.0011 & 0.0004 & $<0.0001$ & & \\
\hline Haemostatic clip & 0.0003 & 0.0003 & $<0.0003$ & & \\
\hline Prototype clip & 0.008 & 0.008 & 0.008 & & \\
\hline Elastic bands & NS & NS & 0.026 & & \\
\hline Endoloop & NS & NS & NS & NS & 0.008 \\
\hline \multicolumn{6}{|l|}{ Endoloop versus } \\
\hline Marker clip & 0.0011 & 0.0004 & $<0.0001$ & & \\
\hline Haemostatic clip & 0.0003 & 0.0003 & 0.0003 & & \\
\hline Prototype clip & $<0.0001$ & $<0.0001$ & $<0.0001$ & & \\
\hline
\end{tabular}

The elastic bands shown are the unstretched bands as the prestretched ones failed to acheive haemostasis.
The prototype was $15 \mathrm{~mm}$ long whereas the other two types were $10 \mathrm{~mm}$ long. All were administered by means of the endoscopic clip fixing device ${ }^{6566}$ (Olympus HX 3L) which can be passed through a $2.8 \mathrm{~mm}$ diameter biopsy channel of the gastroscope. The thickness of all the clips was the same and all were applied to postmortem gastric mucosa before commencing the study.

\section{Endoscopic sewing machine}

The endoscopic sewing machine ${ }^{61}$ had a suction cavity that was $7.1 \mathrm{~mm}$ wide and 8.7 $\mathrm{mm}$ long. The non-flexible part of the sewing machine which is attached to the distal tip of the gastroscope had a length of $33.1 \mathrm{~mm}$ and diameter of $9.0 \mathrm{~mm}$. The mesenteric vessels were sucked into the suction cavity of the sewing machine; a nylon thread of $0.2 \mathrm{~mm}$ diameter was passed through the tissue around the vessel and the thread was tied with four half hitches.

\section{Endoloops}

Endoloops $^{57}$ (Olympus loops $\mathrm{MH}-477$ ) are detachable snares, circular in shape and made from nylon with an external diameter of 0.46 $\mathrm{mm}$ (fig 2). They can be passed through a 2.8 $\mathrm{mm}$ or greater biopsy channel of an endoscope using the Olympus HX-20 delivery system. Tissue containing the mesenteric vessels was placed into the open loop and the loop was then closed and detached. The process was repeated along the vessel which was then severed.

STATISTICAL COMPARISONS

Fisher's exact test was used for stastical comparisons. A p value of less than 0.05 was regarded as significant.

\section{Results}

\section{CONTROLS}

All of the control vessels ( $n=5$, for each diameter vessel studied) continued to bleed when incised until they were ligated after 30 seconds.

\section{INJECTION SCLEROTHERAPY}

Injection of adrenaline and ethanolamine failed to achieve haemostasis in any of the vessels tested ( $1 \mathrm{~mm}(\mathrm{n}=20), 2 \mathrm{~mm}(\mathrm{n}=20)$, and $3 \mathrm{~mm}$ $(n=5))$. There were no significant differences between injection sclerotherapy and the different types of clips; but both the elastic bands and bipolar diathermy were significantly superior $(\mathrm{p}<0.0001)$ than injection sclerotherapy on $1 \mathrm{~mm}$ and $2 \mathrm{~mm}$ vessels but there was no significant difference on $3 \mathrm{~mm}$ vessels. Both the sewing machine and the endoloop (table 1) were significantly superior to injection sclerotherapy when tested on $1 \mathrm{~mm}$ and $2 \mathrm{~mm}$ $(p<0.0001)$ and $3 \mathrm{~mm}$ vessels $(\mathrm{p}<0.008)$.

\section{BIPOLAR DIATHERMY}

With bipolar diathermy, $1 \mathrm{~mm}$ vessels $(\mathrm{n}=10)$ were effectively electrocoagulated as were most $2 \mathrm{~mm}$ vessels $(8 / 10)$. On the two occasions that the probe failed on the $2 \mathrm{~mm}$ vessels, haemostasis was achieved with a further 10 two second pulses. Bipolar diathermy was ineffective on 3 
mm vessels $(n=5)$ even after 20 two second pulses were given. Bipolar diathermy was significantly more effective than any of the clips $(\mathrm{p}<0.008)$, injection $(\mathrm{p}<0.0001)$, or prestretched bands $(p<0.0001)$ on vessels of $1 \mathrm{~mm}$ and $2 \mathrm{~mm}$ diameter but of equal efficacy $(p=1.0)$ to unstretched bands for vessels of 1 $\mathrm{mm}$ and $2 \mathrm{~mm}$ in external diameter. Both the snare and the sewing machine (table 1) were significantly more effective than bipolar diathermy on $3 \mathrm{~mm}$ vessels $(\mathrm{p}=0.008)$.

\section{MECHANICAL METHODS \\ Elastic bands}

Two types of elastic bands were tested. The prestretched bands (with a mean external diameter of $5.1 \mathrm{~mm}$ and internal diameter of $2.0 \mathrm{~mm}$ ) commercially supplied on the "O" rings were tested and were unable to stop bleeding from vessels of any size on this model. When unstretched haemorrhoidal bands (mean external diameter of $4.5 \mathrm{~mm}$ and internal diameter of $1.4 \mathrm{~mm}$ ) were tested they were successful in stopping bleeding on $1 \mathrm{~mm}(\mathrm{n}=5)$ and $2 \mathrm{~mm}$ vessels (13/15) but failed on $3 \mathrm{~mm}$ vessels $(7 / 10)$. There were no significant differences between the prestretched bands, clips, and injection sclerotherapy. The unstretched bands were significantly more effective than any of the clips $(\mathrm{p}<0.01)$, prestretched bands, or injection sclerotherapy $(\mathrm{p}<0.0001)$ on vessels up to $2 \mathrm{~mm}$ in diameter. These unstretched bands were as effective as bipolar diathermy in stopping bleeding in vessels up to $2 \mathrm{~mm}$ in diameter. The endoloop (table 1) was significantly more effective than unstretched bands only on $3 \mathrm{~mm}$ diameter vessels $(\mathrm{p}<0.0256)$.

\section{Clips}

Three different types of clip were tested: marker clip, haemostatic clip, and the new prototype clip. There was no significant difference in the performance of any of these despite one being termed a haemostatic and another a marker clip.

The marker clip (MD59) failed to stop bleeding on $1 \mathrm{~mm}$ vessels $(17 / 20)$, on $2 \mathrm{~mm}$ vessels $(18 / 20)$, and on $3 \mathrm{~mm}$ vessels $(n=20)$. The haemostatic clips were unable to stop bleeding from $1 \mathrm{~mm}(\mathrm{n}=10), 2 \mathrm{~mm}(\mathrm{n}=10)$, and $3 \mathrm{~mm}$ vessels $(\mathrm{n}=10)$. The longer prototype clips were also unable to stop bleeding

Table 2 Haemostatic efficacy of mechanical, thermal, and injection methods

\begin{tabular}{|c|c|c|c|c|c|}
\hline \multirow[b]{2}{*}{ Haemostatic method } & \multicolumn{5}{|c|}{ Messenteric vessel diameter $(\mathrm{mm})$} \\
\hline & 1 & 2 & 3 & 4 & 5 \\
\hline Control & $0 / 5$ & $0 / 5$ & $0 / 5$ & $0 / 5$ & $0 / 5$ \\
\hline Injection & $0 / 20$ & $0 / 20$ & $0 / 5$ & & \\
\hline \multicolumn{6}{|l|}{ Clips } \\
\hline Marker & $3 / 20$ & $2 / 20$ & $0 / 20$ & & \\
\hline Haemostatic & $0 / 10$ & $0 / 10$ & $0 / 10$ & & \\
\hline Prototype & $0 / 5$ & $0 / 5$ & $0 / 5$ & & \\
\hline \multicolumn{6}{|l|}{ Elastic bands } \\
\hline Preloaded & $0 / 5$ & $0 / 5$ & $0 / 5$ & & \\
\hline Unstretched & $5 / 5$ & $13 / 15$ & $3 / 10$ & & \\
\hline Bipolar diathermy & $10 / 10$ & $8 / 10$ & $0 / 5$ & & \\
\hline Sewing machine & $5 / 5$ & $5 / 5$ & $5 / 5$ & $8 / 10$ & $0 / 5$ \\
\hline Endoloops & $5 / 5$ & $5 / 5$ & $5 / 5$ & $5 / 5$ & $5 / 5$ \\
\hline
\end{tabular}

Results are expressed as the number of times successful haemostasis was achieved/total number of times that the procedure was tested. Bold figures indicate successful haemostasis; the remainder are failures. from $1 \mathrm{~mm}(\mathrm{n}=5), 2 \mathrm{~mm}(\mathrm{n}=5)$, and $3 \mathrm{~mm}$ vessels $(n=5)$. Only 15 prototype clips were available for study. There was no significant difference between any of the clips tested or between the clips and injection sclerotherapy. Clips were significantly less effective than unstretched bands $(\mathrm{p}<0.008)$ or bipolar diathermy $(\mathrm{p}<0.007)$ on vessels up to $2 \mathrm{~mm}$ in diameter and less effective than either the endoloop $(\mathrm{p}<0.001)$ or the sewing machine $(\mathrm{p}<0.008)$ on vessels up to $3 \mathrm{~mm}$ in diameter (table 1). Clips were not tested on vessels of 4 $\mathrm{mm}$ and $5 \mathrm{~mm}$ in diameter but as they were ineffective in stopping bleeding in vessels up to $3 \mathrm{~mm}$ in diameter it is reasonable to suppose that they would be ineffective in vessels above 3 $\mathrm{mm}$ in diameter.

Gentle pessure between thumb and forefinger when applied to the clip achieved complete haemostasis, suggesting that clip modification could improve their effectiveness. The shape of these clips made haemostasis unlikely as on closure of the clip there is a gap between the two blades of the clip (approximately $0.6 \mathrm{~mm}$ ), with only the distal end of the clip in apposition.

\section{Sewing machine}

Complete haemostasis was achieved on vessels of $1 \mathrm{~mm}(\mathrm{n}=5), 2 \mathrm{~mm}(\mathrm{n}=5), 3 \mathrm{~mm}(\mathrm{n}=5)$, and $4 \mathrm{~mm}(8 / 10)$ vessels using the endoscopic sewing machine. However it was unable to stop bleeding from $5 \mathrm{~mm}$ vessels $(n=5)$ because the vessel was too large to be sucked into the cavity so that the needle and thread could not be passed completely round the vessel complex. The sewing machine was significantly more effective than injection sclerotherapy on 1-3 $\mathrm{mm}$ vessels $(\mathrm{p}<0.008)$, and was more effective than bipolar diathermy $(p=0.008)$ and unstretched bands $(p=0.026)$ on vessels of $3 \mathrm{~mm}$ diameter. The endoloop (table 1) was significantly more effective than the sewing machine on $5 \mathrm{~mm}$ vessels $(\mathrm{p}=0.008)$.

\section{Endoloop}

Complete haemostasis was achieved on all vessels tested: $1 \mathrm{~mm}(\mathrm{n}=5), 2 \mathrm{~mm}(\mathrm{n}=5), 3 \mathrm{~mm}$ $(n=5), 4 \mathrm{~mm}(n=5)$, and $5 \mathrm{~mm}(\mathrm{n}=5)$. Haemostasis was even achieved on a $12 \mathrm{~mm}$ external diameter splenic artery and vein. The endoloop was more effective than injection sclerotherapy $(\mathrm{p}<0.008)$, clips $(\mathrm{p}<0.0011)$, and prestretched bands on vessels up to $3 \mathrm{~mm}$ in diameter. There was no significant difference in efficacy between endoloops and either unstretched bands or bipolar diathermy on vessels up to $2 \mathrm{~mm}$ in diameter. The endoloop was however more effective than unstretched bands $(p=0.0256)$ and bipolar diathermy $(p=0.008)$ on vessels of $3 \mathrm{~mm}$ in diameter. It proved superior to the sewing machine only on vessels of $5 \mathrm{~mm}$ in diameter $(\mathrm{p}=0.0008)$. The endoloop was the only endoscopic method that was able to stop bleeding from vessels larger than $4 \mathrm{~mm}$ in diameter.

OVERALL EFFICACY

In this study the most effective mechanical methods-endoloops and sewing machine- 
were able to stop bleeding from vessels of 1-4 $\mathrm{mm}$ in diameter (table 2). Mechanical methods of haemostasis (endoloops or sewing machine) were significantly more effective in controlling haemorrhage from large vessels than injection or thermal methods.

\section{Discussion}

This randomised controlled study clearly shows that the best mechanical methods (sewing machine and endoloops) were more effective in stopping bleeding from vessels of 1-4 $\mathrm{mm}$ than either injection or thermal methods. Mechanical methods alone were able to provide secure haemostasis for all sizes of blood vessels found in human peptic ulcers.

Injection of adrenaline and ethanolamine was ineffective in this model and did not stop bleeding in vessels of 1-2 mm diameter. Most published studies in animal models suggest that injection methods can reduce blood flow but do not stop bleeding. Submucosally applied adrenaline has been shown in a rat model ${ }^{67}$ to cause a reduction in local gastric blood flow. Adrenaline, absolute ethanol, or polidocanol showed a reduction in bleeding in standard canine ulcers with an external diameter less than $0.5 \mathrm{~mm}^{37} 68$ but complete haemostasis was only achieved in $2 / 10$ ulcers treated with adrenaline. ${ }^{68}$

Absolute ethanol ${ }^{36}$ was the most effective agent in causing arterial coagulation in canine serosal vessels of $0.5 \mathrm{~mm}$ diameter. Normal saline, hypertonic saline, adrenaline, and thrombin reduced the bleeding rate in serosal vessels of $1.6 \mathrm{~mm}$ to $2.1 \mathrm{~mm}$ but complete haemostasis ranged from $0 \%$ (normal saline) to $47 \%$ (adrenaline plus hypertonic saline) ${ }^{69}$ Adrenaline and polidocanol were ineffective in canine mesenteric vessels greater than $0.5 \mathrm{~mm}$ in external diameter. ${ }^{37}$

Injection is so ineffective in achieving complete haemostasis in animal studies that it is surprising it has done as well in clinical trials as the reports suggest. There is an apparently convincing body of evidence for clinical efficacy of injection sclerotherapy including retrospective studies, ${ }^{70}$ randomised controlled studies, ${ }^{14-16} 22$ and meta-analyses. ${ }^{1-3}$

Bipolar diathermy has been shown to stop bleeding in canine ulcer models on vessels from $0.5 \mathrm{~mm}^{38}{ }^{40-43}$ and on isolated canine mesenteric vessels up to $2 \mathrm{~mm}^{38}{ }^{39}$ diameter. Several randomised controlled trials ${ }^{121328}$ and meta-analyses ${ }^{1-3} 71$ support the clinical efficacy of bipolar electrocoagulation in human peptic ulcer bleeding ${ }^{8}$ although there are some randomised clinical trials that have failed to show significant differences between bipolar electrocoagulation and injection sclerotherapy. ${ }^{120}$

Prestretched elastic bands in this study failed to achieve haemostasis on vessels of $1 \mathrm{~mm}$ or greater. Despite this there is a fair body of clinical evidence of efficacy for these unstretched bands in the treatment of bleeding varices $^{49} 505253$ which includes meta-analysis ${ }^{54}$ and reports of successful treatment of bleeding gastric ulcers ${ }^{55}$ and angiodysplasia. ${ }^{56}$ This is the first report to suggest that fatigue of the elastic material may be one factor contributing to haemostatic failure with banding. When the bands were replaced with unstretched latex bands haemostasis was achieved in vessels up to $2 \mathrm{~mm}$.

All the clips studied failed to secure haemostasis. This failure is due to two features intrinsic to the design of these clips: the shape of the clip and the limited force that the clip can exert at its distal end. On closure of the clip, only the distal end is in apposition and there is a gap between the two limbs of the clip of $0.6 \mathrm{~mm}$ resulting in very little pressure being exerted on a part of the bleeding vessel. This probably indicates that a different tip configuration to the clip is required to compress the lumen of the vessel. A small amount of finger pressure applied to the limbs of the clips following their application achieved haemostasis. More force is therefore required to compress the vessel than is able to be produced with present endoscopic methods. The haemoclip has been reported to be successful in uncontrolled studies of both variceal ${ }^{46}$ and non-variceal ${ }^{47}{ }^{48}$ upper gastrointestinal bleeding, though a rebleed rate of around $11 \%$ still occurred. Provisional results from a randomised trial comparing clips and adrenaline with injection of adrenaline only showed a trend towards lower rebleeding for clips and injection in comparison with injection $^{72}$ only.

Although the sewing machine seems promising in achieving haemostasis in vessels up to 4 $\mathrm{mm}$ its application in the clinical treatment of varices or bleeding ulcers is unproven. It has been used to underrun standard experimental bleeding ulcers. ${ }^{61}$ This method requires tissue to be sucked into the cavity of the sewing machine and once the thread has been passed requires the extracorporeal tying of four half hitches. The limitation on securing haemostasis on vessel size above $4 \mathrm{~mm}$ in diameter is due to the size of the suction cavity and by increasing the size of the suction cavity an increase in size of vessel haemostasis might be achieved. Possible drawbacks are that heavily scarred tissue occasionally found in peptic ulcers may not be able to be drawn into the cavity. Even if tissue could be drawn into the cavity, the force that is required to pass a needle deeply through scarred tissue and back out again to ligate- - for instance, the gastroduodenal artery is greater than the force that can be applied at flexible endoscopy with present methods. Furthermore the tying of four half hitches ${ }^{73}$ using an extracorporeal method means that, at present, six passes of the gastroscope are needed for each stitch thrown.

In this study endoloops were the only method that stopped bleeding from all sizes of vessels studied. Unfortunately it was difficult to deploy the endoloops in a manner that would be easy to achieve at flexible endoscopy in bleeding peptic ulcer. The mesenteric vessels had to be placed using forceps into the endoloop before closure. An improved method of endoscopic delivery is required, but if this could be achieved it might allow improved haemostasis if it could be applied. Preliminary work $^{74}{ }^{75}$ suggests that the use of a suction end 
cap and modification of the endoloop may allow easier application.

This animal model ${ }^{36}{ }^{40}$ was used as it allowed the limits of haemostatic efficacy to be assessed for each endoscopic method tested. The standard canine bleeding ulcer model that has been used by other groups, ${ }^{3841} 4268$ which was initially developed by Protell et $a l^{7^{6}}$ and modified by Dennis et $a l^{77}$ was not used because the maximum diameter of vessels obtained has been estimated to be only 0.5 $\mathrm{mm}$. It is known that human peptic ulcers can erode into vessels of diameters $0.1-3.45 \mathrm{~mm}$ (bleeding vessels from postoperative specimens of bleeding gastric ulcer range from 0.1 to 1.8 $\mathrm{mm},{ }^{35}$ but in postmortem gastric and duodenal ulcers bleeding vessels range from 0.3 to 3.45 $\mathrm{mm}$ and from 0.1 to $3.45 \mathrm{~mm}$ respectively ${ }^{34}$ ). This model therefore allows haemostatic methods to be applied to vessels which have been accurately measured and include the sizes of vessels that can be found in human bleeding peptic ulcers, especially those with large eroded arteries.

Although injection and thermal methods seem to offer efficacy in clinical studies the inability of these methods to arrest bleeding in this model suggests that these methods may be of limited clinical efficacy when used on large vessels as found in some cases of human peptic ulcer bleeding. Perhaps fortunately, most bleeding gastric ulcers in our pathological studies $^{34}{ }^{35}$ bled from arteries that were smaller than $1 \mathrm{~mm}$ in diameter (mean diameter 0.9 $\mathrm{mm}$ ) while a minority bled from larger vessels up to $3.45 \mathrm{~mm}$. This might explain why the injection methods which uniformly failed to stop bleeding in this study seem to produce positive results in some randomised controlled trials. It is not very likely that minor methodological alterations in injection or thermal methods will much improve results.

Access is different when treating bleeding at flexible endoscopy or at laparotomy. In general the view is superior at flexible endoscopy but the ability to manipulate the bleeding rate is less; injection of adrenaline may help but it is harder at endoscopy to apply direct pressure to a bleeding vessel in order to control the bleeding while treatment is applied. Severe bleeding can limit access more at endoscopy than surgery. Deep duodenal ulcers and some high lesser curve ulcers can be difficult to access at flexible endoscopy.

The ability to apply treatment is also somewhat different at open surgery when compared with flexible endoscopy. At surgery, a strong force can be applied to compress a vessel or to get instruments to pass either side of a bleeding artery; at flexible endoscopy a maximum of 100-150 $\mathrm{g}$ force ${ }^{40}$ can be applied however hard an accessory is pushed through a biopsy channel. It is probable that most methods that can be shown to work well at surgery may be sometimes more difficult to apply at flexible endoscopy. Coaptation (compression with subsequent welding of the endothelial surfaces of a blood vessel) of a bleeding vessel is sometimes possible using thermal probes but is not that reliable or easy to achieve during flexible endoscopy. At surgery, access can be achieved from a variety of angles. At endoscopy, only one angle is generally feasible; this is usually acute and a 90 degree approach is only occasionally possible for some gastric ulcers.

The bleeding site seen in bleeding ulcers at flexible endoscopy differs from the mesenteric vessels that were studied in certain respects. Pathological studies show the tendency of the bleeding vessel to loop up to protrude or be eroded close to the floor of the ulcer. It is not possible to identify the orientation of the vessel in an ulcer at flexible endoscopy while the orientation of the mesenteric vessel is easy to see. It is probably more difficult at flexible endoscopy to flatten the vessel or to get mechanical, injection, or thermal methods to have an effect on the back wall of the bleeding vessel which is more inaccessible than at surgery. Peptic ulcers are exposed to acid and mesenteric vessels are not. The eroded artery in a bleeding peptic ulcer features acute and/or chronic inflammatory changes, including destruction of the outer wall over a variable length, fibrinoid necrosis, and a polymorphonuclear cell infiltrate which is not seen in the mesenteric vessels that were studied; this may make the application of mechanical, thermal, and injection methods more difficult. This pathology may also make recurrent bleeding after treament more likely.

The presence of scar tissue with reduced compliance is a problem that applies to all mechanical methods. Methods that require suction to conform the ulcer into a shape that would allow the band, endoloop, or sewing machine methods to work in their current configuration are likely to work less well in heavily scarred ulcers. The clips are also less likely to work well in the presence of scarring. It can be technically difficult even at open surgery to pass a tie accurately round the bleeding vessel and even much stronger mechanical clips as used at open or laparoscopic surgery may not work well in the presence of scar tissue or a necrotic vessel.

We were surprised in this study to find that the most commonly used mechanical methods of haemostasis (clips and prestretched bands) were unable to achieve haemostasis even on 1 $\mathrm{mm}$ vessels. The force that can be exerted by the different mechanical methods is an important determinant of efficacy. The bands and clips failed to work because the force exerted on the bleeding vessel was insufficient or could not be maintained. Much more mechanical force can be exerted by a tied knot or a closed endoloop at flexible endoscopy. It is easier to exert more longitudinal force of pull type at flexible endoscopy than lateral force as exerted by bands and clips.

Despite these differences it remains true that the basic principles of surgical haemostasis should be applied to flexible endoscopic methods. This study shows that injection and to some extent thermal methods are relatively weak as haemostatic methods. Only mechanical methods were able to secure haemostasis from the larger vessels that might be encountered in bleeding peptic ulcers. Relatively little 
engineering effort has gone into developing mechanical endoscopic methods for use with a flexible endoscope. If improvements are to be made in securing haemostasis and hence improving morbidity and mortality from bleeding peptic ulcer, it seems likely that mechanical methods will have to be developed for endoscopic use which are more effective on large vessels and are easier to use and deliver than at present.

The work was carried out at the Gastrointestinal Science Research Unit, St Bartholomew's and The Royal London School of Medicine and Dentistry, London E1 2AJ, UK. This study was supported by a Wellcome Trust grant (no 042997/2 94A).

1 Sacks HS, Chalmers TC, Blum AL, et al. Endoscopic haemostasis: an effective therapy for bleeding peptic ulcers. haemostasis: an effective

2 Henry D, Cook D. Meta-analysis workshop in upper gastrointestinal hemorrhage. Gastroenterology 1991;100: 1481-2.

3 Cook DJ, Guyatt GH, Salena BJ, et al. Endoscopic therapy for acute nonvariceal upper gastrointestinal haemorrhage: a meta analysis. Gastroenterology 1992;102:139-48.

4 Swain CP, Kirkham JS, Salmon PR, et al. Controlled trial of YAG laser treatment of upper digestive haemorrhage. Lancet 1986;i:1113-18.

5 Rutgeerts P, Vantrappen G, Broeckart L, et al. Controlled trial of YAG laser treatment of upper digestive haemorrhage. Gastroenterology 1982;83:410-6.

6 Macleod IA, Mills PR, Mackenzie JF, et al. Neodymium yttrium aluminium garnet laser photocoagulation for major haemorrhage from peptic ulcers and single vessels: a single blind controlled trial. BMF 1983;286:345-8.

7 Matthewson K, Swain CP, Bland M, et al. Randomised comparisonof Nd-YAG laser, heater probe and no endoscopic therapy for bleeding peptic ulcer. Gastroenterolendoscopic therapy for
ogy 1990;98:1239-44.

8 Consensus Development Panel. National Institutes of Health consensus statement on therapeutic endoscopy and Health consensus statement on therapeutic endosco
bleeding ulcers: Gastrointest Endosc 1990;36:S62-5.

9 Swain CP, Bown SG, Storey DW, et al. Controlled trial of argon laser photocoagulation in bleeding peptic ulcers. Lancet 1981;ii:1313-6.

10 Freitas D, Donato A, Monteiro JG. Controlled trial of liquid monopolar electrocoagulation in bleeding peptic ulcers. Am F Gastroenterol 1985;80:853-7.

11 Moretó M, Zaballa M, Ibáñez S, et al. Efficacy of monopolar electrocoagulation in the treatment of bleeding gastric ulcer: a controlled trial. Endoscopy 1987;19:54-6.

12 Laine LA. Multipolar electrocoagulation in the treatment of active upper gastrointestinal tract haemorrhage. A prospective controlled trial. N Engl f Med 1987;316:1613-7.

13 Laine LA. Multipolar electrocoagulation in the treatment of peptic ulcers with non-bleeding visible vessels; a prospective controlled trial. Ann Intern Med 1989;110:510-4.

14 Rutgeerts P, Vantrappen G, Broekaert L, et al. Comparison of endoscopic polidocanol injection and YAG laser therapy of endoscopic polidocanol injection and YAG laser

15 Rutgeerts P, Gevers AM, Hiele M, et al. Endoscopic injection therapy to prevent rebleeding from peptic ulcers with a protruding vessel: a controlled comparative trial. Gut 1993;34:348-50.

16 Oxner RBG, Simmonds NJ, Gertner DJ, et al. Controlled trial of endoscopic injection treatment for bleeding from peptic ulcers with visible vessels. Lancet 1992;339:966-8.

17 Panés J, Viver J, Forné $\mathrm{M}$, et al. Controlled trial of endoscopic sclerosis in bleeding peptic ulcers. Lancet 1987; ii: $1292-4$.

18 Chung SCS, Leung JWC, Steele RJC, et al. Endoscopic injection of adrenaline for actively bleeding ulcers: a randomized trial. BMF 1988;296:1631-3

19 Moretó M, Zaballa M, Suárez MJ, et al. Endoscopic local injection of ethanolamine oleate and thrombin as an effective treatment for bleeding duodenal ulcer: a controlled tive treatment for bleeding

20 Laine L. Multipolar electrocoagulation vs injection therapy in the treatment of bleeding peptic ulcers: a prospective, randomised trial Gastroenterology 1990;99:1303-6.

21 Hui WM, Ng MMT, Lok ASF, et al. A randomised comparative study of laser photocoagulation, heater probe, and bipolar electrocoagulation in the treatment of actively bleeding ulcers. Gastrointest Endosc 1991;37:299-304.

22 Panés J, Vivier J, Forné M. Randomized comparison of endoscopic microwave coagulation and endoscopic sclerosis in the treatment of bleeding peptic ulcers. Gastrointest Endosc 1992;37:611-16.

23 Choudhari CP, Palmer KR. Endoscopic injection therapy for bleeding peptic ulcer; a comparison of adrenaline alone with adrenaline plus ethanolamine oleate. Gut 1994;35: 608-10.

24 Choudhari CP, Rajgopal C, Palmer KR. Comparison of endoscopic injection therapy versus the heater probe in major peptic ulcer haemorrhage. Gut 1992;33:1159-61.

25 Loizou LA, Bown SG. Endoscopic treatment for bleeding peptic ulcers: randomised comparison of adrenaline injec- tion and adrenaline injection + Nd:YAG laser photocoagulation. Gut 1991;32:1100-3.

26 Chung SCS, Leung JWC, Leong HT, et al. Adding a sclerosant to endoscopic epinephrine injection in actively bleeding ulcers: a randomised trial. Gastrointest Endosc 1993;39: $611-15$

27 Chung SCS, Leung JWC, Sung JY, et al. Injection or heat probe for bleeding ulcer. Gastroenterology 1991;100:33-7.

28 Lin HJ, Lee FY, Kang WM, et al. Heat probe thermocoagulation and pure alcohol injection in massive peptic ulcer haemorrhage: a prospective, randomised controlled trial. Gut 1990;31:753-7.

29 Krejs GJ, Little KH, Westergaard H, et al. Laser photocogulation for the treatment of acute peptic-ulcer bleeding. N Engl 7 Med 1987;316:1618-21.

30 Waring JP, Sanowski RA, Sawyer RL, et al. A randomized comparison of multipolar electrocoagulation and injection clerosis for the treatment of bleeding peptic ulcer. Gastrointest Endosc 1991;37:295-8.

31 Vallon AG, Cotton PB, Laurence $\mathrm{BH}$, et al. Randomized trial of endoscopic argon laser photocoagulation in bleeding peptic ulcers. Gut 1981;22:228-32.

32 Lin HJ, Tsai YT, Lee SD, et al. A prospectively randomised trial of heat probe thermocoagulation versus pure alcohol injection in nonvariceal peptic ulcer haemorrhage. Am $\mathcal{F}$ Gastroenterol 1988;83:283-6.

33 Lin HJ, Perng CL, Lee FY, et al. Endoscopic injection for the arrest of peptic ulcer haemorrhage: final results of a prospective, randomised comparative trial. Gastrointest Endosc 1993;39:1519.

34 Lai KC, Swain CP. The size of vessel in patients dying from bleeding gastric ulcer [abstract]. Gastroenterology 1993;104: A202.

35 Swain CP, Storey D, Bown S, et al. Nature of the bleeding vessel in recurrently bleeding gastric ulcers. Gastroenterology 1986;90:595-608.

36 Randall GM, Jensen DM, Hirabayashi K, et al. Controlled study of different sclerosing agents for coagulation of canine gut arteries. Gastroenterology 1989;96:1274-81.

37 Kalabakas AA, Porter AJ, Mule L, et al. Design of a microwave system for endoscopy: an experimental study of energy, tissue contact, and hemostatic efficacy. Gastroenterology 1993;104:680-9.

38 Michaeletz PA, Judge D. Microwave energy compared with heater probe and BICAP in canine models of peptic ulcer hemorrhage. Gastroenterology 1989;97:676-84.

39 Johnston JH, Jensen DM, Auth D. Experimental comparison of endoscopic yttrium-aluminium-garnet laser, electrosurgery and heater probe for canine gut arterial coagulation. Gastroenterology 1987;92:1101-8.

40 Swain CP, Mills TN, Shemesh E, et al. Which electrode? A comparison of four endoscopic methods of electrocoagulation in experimental bleeding ulcers. Gut 1984;25:1424-

41 Johnston JH, Jensen DM, Mautner W. Comparison of endoscopic electrocoagulation and laser photocoagulation of bleeding canine gastric ulcers. Gastroenterology 192;82:90410

42 Machicado GA, Jensen DM, Tapia JL, et al. Treatment of bleeding canine and duodenal and esophageal ulcers with argon laser and bipolar electrocoagulation. Gastroenterology 1981;81:859-65.

43 Dennis MB, Peoples J, Hulett R, et al. Evaluation of electrofulguration in control of bleeding of experimental gastric ulcers. Dig Dis Sci 1979;24:845-8.

44 Carter DC, Johnstone JMS. Operations on the stomach and duodenum. In: Farquharson's textbook of operative surgery. 7th edn. New York: Churchill Livingstone, 1986:358.

45 Meilahn JE, Ritchie Jr WP. Bleeding gastric or duodenal ulcer. In: Atlas of general surgery. 3rd edn. London: Chapman and Hall Medical, 1996:287-90.

46 Miyoshi H, Shikata J, Tokura Y. Endoscopic clipping of esophageal varices. Digestive Endoscopy 1992;4:147-50.

47 Binmoeller KF, Thonke F, Soehendra N. Endoscopic hemoclip treatment for gastrointestinal bleeding. Endoscopy 1993;25:167-70.

48 Takahashi H, Fujita R, Sugiyama K, et al. Endoscopic hemostasis in hemorrhagic gastric ulcer-effectiveness of the hemoclipping, ethanol injections and heat probe. Digestive Endoscopy 1991;3:498-504.

49 Stiegmann GV, Goff JS, Michaletz-Onody PA, et al. Endoscopic sclerotherapy as compared with endoscopic ligation for bleeding oesophageal varices. $N$ Engl $f \mathrm{Med}$ 1992;326:1527-32.

50 Laine L, El-Newihi HM, Migikovsky B, et al. Endoscopic ligation compared with sclerotherapy for the treatment of bleeding esophageal varices. Ann Intern Med 1993;119:1-7.

51 Gimson AE, Ramage JK, Panos MZ, et al. Randomised trial of variceal banding ligation versus injection sclerotherapy for bleeding oesophageal varices. Lancet 1993;342:391-4.

52 Hashizume M, Ohta M, Ueno K, et al. Endoscopic ligation of oesophageal varices compared with injection Endorc 1993;39:123-6.

53 Young MF, Sanowski RA, Rasche R. Comparison and characterization of ulcerations induced by endoscopic ligaton of esophageal varices versus endoscopic sclerotherapy. Gastrointest Endosc 1993;39:119-22.

54 Laine L, Cook D. Endoscopic ligation compared with sclerotherapy for treatment of esophageal variceal bleeding. A meta-analysis. Ann Intern Med 1995;123:280-7.

55 Tseng C, Burke S, Connors P, et al. Endoscopic band ligation for treatment of non-variceal upper gastrointestinal bleeding. Endoscopy 1991;23:297-8. 
56 Campo R, Brullet E. Endoscopic treatment of gastric angiodysplasia with elastic band ligation. Gastrointest Endosc dysplasia with

57 Hachisu T. A new detachable snare for hemostasis in the removal of large polyps or other elevated lesions. Surg Endosc 1991;5:70-

58 Yoshida T, Hayashi N, Suzumi N, et al. Endoscopic ligation of gastric varices using a detachable snare. Endoscopy 1994 26:502-5.

59 Escourou J, Delvaux M, Buscail L, et al. First clinical evaluation and experimental study of a new mechanical suture device for endoscopic hemostasis. Gastrointest Endosc 1990; 36:494-7.

60 Taylor TV. Isolated duodenal tamponade for treatment of bleeding duodenal ulcer. Lancet 1988;i:911-2.

61 Swain CP, Mills TN. An endoscopic sewing machine. Gastrointest Endosc 1986;32:36-8.

62 Swain CP, Brown GJ, Mills TN. An endoscopic stapling device: the development of a new flexible endoscopically controlled device for placing multiple transmural staples in gastrointestinal tissue. Gastrointest Endosc 1989;35:338 in g.

63 Swain CP, Mills TN, Northfield TC. Experimental studies of new mechanical methods of endoscopic haemostasis stitching, banding, clamping and ulcer removal [abstract] Gut 1985;26:A1151.

64 Van Stiegman G, Cambre T, Sun JH. A new endoscopic elastic band ligating device. Gastrointest Endosc 1986;32:230-3.

65 Hachisu T. Evaluation of endoscopic hemostasis using an improved clipping apparatus. Surg Endosc 1988;2:13-17.

66 Hachisu T, Miyazaki S, Hamaguchi K. Endoscopic clip-marking of lesions using the newly developed HX-3L clip. Surg Endosc 1989;3:142-7.

67 Chung SCS, Leung JWC, Leung FW. Effect of submucosal epinephrine injection on local gastric blood flow. A study using laser doppler flowmetry and reflectance spectrophotometry. Dig Dis Sci 1990;35:1008-11.

68 Rutgeerts P, Geboes K, Vantrappen G. Experimental studies of injection therapy for severe nonvariceal bleeding in dogs. Gastroenterology 1989;97:610-21.

69 Whittle TJ, Sugawa C, Lucas CE, et al. Effect of haemostatic agents in canine serosal blood vessels. Gastrointest Endosc 1991;37:305-9.

70 Chen JJ, Changchien CS, Tai DI, et al. Success of endoscopic injection therapy in correlation with maximal one-day transfusion requirement. Endoscopy 1995;27:298-302.

71 Lam SK, Lai KC. Endoscopic haemostasis for gastrointestinal bleeding: the dawning of a new era. 7 Gastroenterol nal bleeding: the dawnin
Hepatol 1994;9:69-74.

72 Villaneuva C, Balanzó J, Sàbat M, et al. Injection therapy alone or with endoscopic hemoclip for bleeding peptic ulcer. Preliminary results of a randomized trial. Gastrointest Endosc 1996;43:361.

73 Swain CP, Kadirkamanathan SS, Gong F, et al. Knot tying at flexible endoscopy. Gastrointest Endosc 1994;40:722-9.

74 Hepworth CC, Gong F, Kadirkamanathan SS, et al. Experimental and clinical studies of endoloops: a new method of mechanical haemostasis for oesophageal varices [abstract]. Gut 1995;37(suppl 2):A1.

75 Hepworth CC, Kadirkamanathan SS, Lauffer J, et al. Multiple firing endoloops: a new treatment for varices. Br F Surg 1996:83(suppl 1);28.

76 Protell RL, Silverstein FE, Piercey MD, et al. A reproducible animal model of acute bleeding ulcer-the "ulcer maker". Gastroenterology 1976;71:961-4.

77 Dennis BM, Silverstein FE, Gilbert DA, et al. Evaluation of Nd:YAG photocoagulation using a new experimental ulcer model with a single bleeding artery. Gastroenterology 1981; 80:1522-7. 